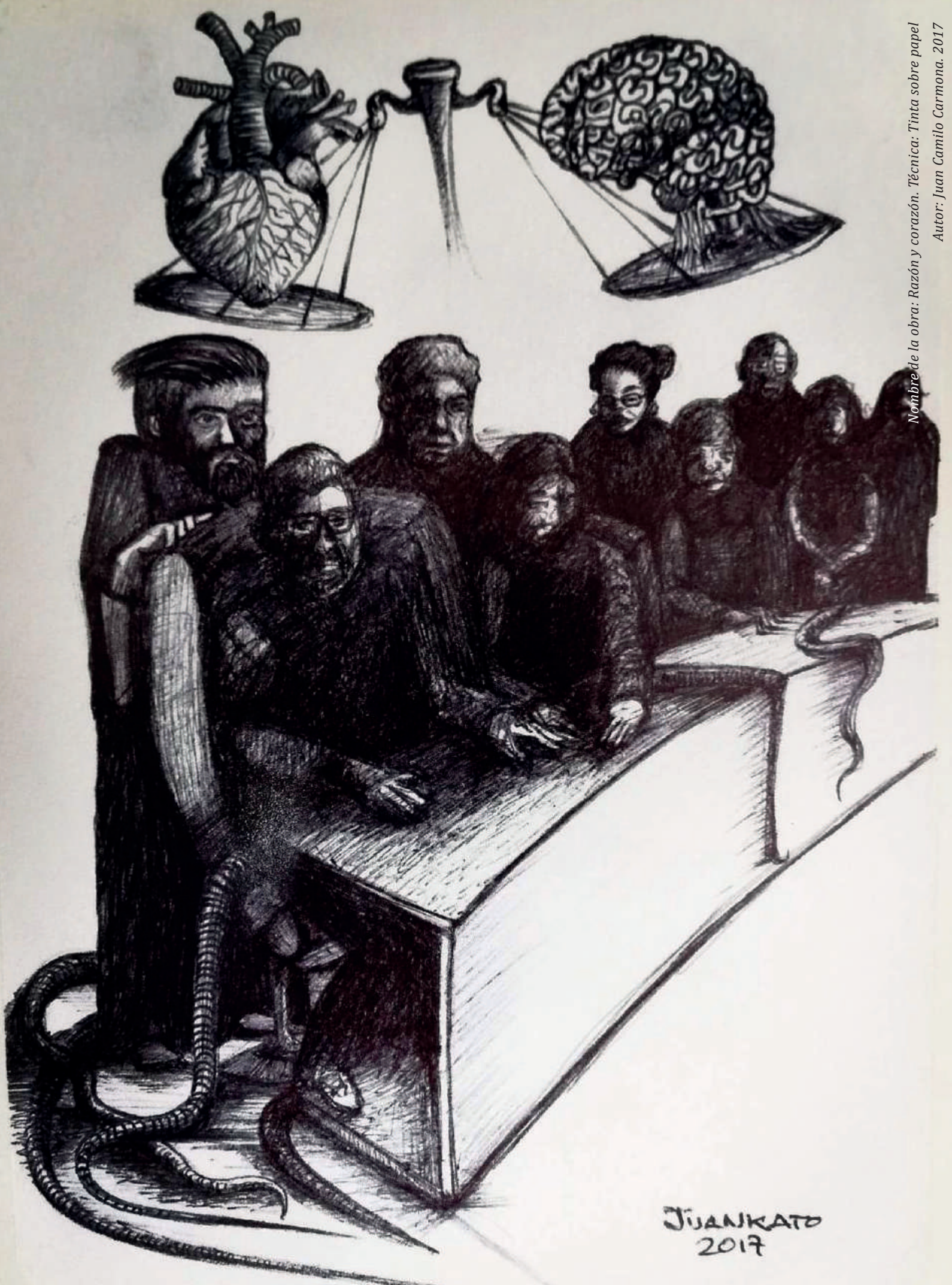




\title{
Un análisis crítico en torno a la relación entre democracia y corrupción: el caso México*
}

\author{
Felipe Curcó Cobos **
}

\section{Resumen}

Este artículoargumenta que democraciay corrupción sonvariables endógenas, es decir,variables que secondicionan recíprocamente. Además su com portamiento está determinado por otras variables sistémicasusualmente difíciles de observar y cuantificar. Prácticas corruptas obstaculizan la consolidación de la democracia y una democracia mal consolidada genera corrupción. Este carácter endógeno es la causa de que la literatura especializada no sea conclusiva respecto a si existe o no una correlación lineal negativa ente democracia y corrupción. Parailustrar esta tesis analizo el caso representativo de México. Si bien tanto la impunidad como la corrupción han sido constantes en la historia del desarrollo de ese país, ambas han tenido una elevación exponencial y descontrolada a raíz de que en el año 2000 iniciara el proceso de democratización que puso fin al régimen de partido único de Estado. En el caso de México no hay duda de que mayor democracia ha significado mucho mayor corrupción, a la par que la corrupción haimpedidola consolidacióndemocrática. Analizarécuáles sonlos mecanismos causales que permiten explicar esto. Finalizaré concluyendo que, no obstante lo anterior, la única solución viable a este problema pasa por el robustecimiento del Estado de Derecho y las instituciones democráticas.

Palabras clave: corrupción; democracia; instituciones extractivas; instituciones inclusivas.

\section{A critical analysis on the relation between democracy and corruption: the case of Mexico}

\begin{abstract}
This paper argues that democracy and corruption are endogenous variables, that is, variables that are reciprocally conditioned. Furthermore, their behavior is determined by other systemic variables usually difficult to observe and quantify. Corrupt practices hamper the consolidation of democracy and a poorly consolidated democracy generates corruption. This endogenous character is the reason why the specialized literature is not conclusive as to whether there is or not a negative linear correlation between democracy and corruption. To illustrate this thesis, I analyze the representative case of Mexico. While both impunity and corruption have been constant in the history of the development of this country, both have had an exponential and uncontrolled rise after the beginning of the democratization process in 2000 when the single-party regime of State ended. In the case of Mexico, there is no doubt that greater democracy has meant much more corruption, while corruption has impeded democratic consolidation. I will analyze the causal mechanisms that explain this, concluding that, notwithstanding the foregoing, the only viable solution to this problem is the strengthening of the rule of law and democratic institutions.

Keywords: corruption; democracy; extractive institutions; inclusive institutions.
\end{abstract}

\section{Uma análise crítica em torno da relação entre democracia e corrupção: o caso do México}

\section{Resumo}

Este artigo argumenta que democracia e corrupção são variáveis endógenas; isto é, variáveis que se condicionam de maneira recíproca. Além disso, o seu comportamento está determinado por outras variáveis sistêmicas geralmente dificeis de se observar e quantificar. Práticas corruptas obstaculizam a consolidação da democracia e uma democracia mal consolidada gera corrupção. Esse caráter endógeno é a causa de que a literatura especializada não seja conclusiva sobre a existência ou não de uma correlação linear negativa entre democracia e corrupção. Para ilustrar esta tese analiso o caso representativo do México. Embora tanto a impunidade quanto a corrupção tenham sido constantes na história do desenvolvimento desse país, ambas têm tido uma elevação exponencial e descontrolada em virtude de que no ano 2000 iniciou o processo de democratização que pôs fim ao regime de partido único de Estado. No caso do México não há dúvida de quemai or democracia significou maior corrupção, ao mesmo tempoquea corrupçãoimpediua consolidação democrática. Analisarei quais são os mecanismos causais que permitem explicar isto. Finalizarei concluindoque, contudo, a única solução viável a este problema passa pelo fortalecimento do estado de direito e das instituições democráticas. Palavras-chave: corrupção; democracia; instituições extrativas; instituiçôes inclusivas.

\footnotetext{
* Artículo de reflexión. Investigador único: Felipe Curcó Cobos. Este artículo se hizo bajo financiación del Instituto Tecnológico Autónomo de México. Proyecto de investigación: violencia, criminalidad y corrupción (investigación en curso).

** Doctor en Teoría Política de la Universidad de Barcelona, España. Actualmente es profesor titular de tiempo completo en el Departamento Académico de Ciencia Política del Instituto Tecnológico Autónomo de México, México. Pertenece al Sistema Nacional de Investigadores de su país. Correo electrónico: fcurco@yahoo.es ORCID: 0000-0001-9812-0710
}

Cómo citar este artículo: Curcó, F. (2019). Un análisis crítico en torno a la relación entre democracia y corrupción: el caso México. Estudios de Derecho, 76 (167), pp-pp. 41-64 


\section{Un análisis crítico en torno a la relación entre democracia y corrupción: el caso México}

\section{Introducción}

Desde el final de la Segunda Guerra Mundial han proliferado los estudios dirigidos a evaluar el desempeño de las democracias. Intensamente se ha buscado establecer los vínculos entre democracia liberal y crecimiento económico, redistribución del ingreso y reducción de la corrupción. El resultado es que hoy día - pese a la abundancia en el análisis - no existen en la literatura resultados concluyentes respecto a si la democracia exhibe o no una mayor capacidad que las autocracias para abatir la corrupción, generar igualdad social (medida en términos del coeficiente de Gini) o potenciar el desarrollo económico.

Veamos primero el caso del crecimiento y la redistribución. Usando una amplia base de datos provenientes de Denninger y Squiere (1996), Przeworski (2000, p.149) se ha encontrado que la desigualdad realmente no difiere significativamente entre democracias y autocracias para cada nivel de ingreso (medida la desigualdad por la proporción del $20 \%$ más alto con relación al $20 \%$ que recibe el ingreso más bajo). De modo paralelo, Drury, Krieckhaus y Lusztig (2006) han sugerido que las democracias liberales solo tienen un efecto indirecto en el crecimiento económico y no necesariamente exhiben un mejor desempeño en este rubro que regímenes de corte totalitario. Similares resultados encontramos, por ejemplo, en Baum y Lake (2003) y Heliwell (1994).

Al mismo tiempo, parece no haber duda del nocivo y muy corrosivo efecto que la corrupción tiene en casi todos los índices de bienestar de una nación. Mientras que los estudios no terminan de ponerse de acuerdo respecto al impacto que la democracia tiene en variables como el PIB o la redistribución, los especialistas coinciden abrumadoramente en los perjudiciales efectos de las prácticas corruptas: éstas inhiben el desarrollo (Chowdhury, 2004, p.2), impiden el crecimiento económico (Rose-Ackerman, 1996, p.83); (Mauro 1995, p.104) y también imposibilitan el combate a la pobreza (Transparency International, 2010). Además, claramente erosionan de modo dramático y sistémico el capital financiero, político y humano del que dispone una nación, pues desvían recursos que podrían destinarse a fines 
sociales, resquebrajan el imperio de la ley y debilitan la confianza ciudadana en las instituciones.

Es evidente, por tanto, que la corrupción es uno de los principales problemas globales de nuestro tiempo. Por ello es importante empezar por aclarar que la corrupción no es un delito, sino un bolsón de delitos. Tal y como lo específica claramente el Capítulo III de la Convención de Naciones Unidas Contra la Corrupción, la corrupción no se define como una transgresión simple. Consiste, más bien, en todo un conjunto de quebrantamientos constitutivos de una vasta variedad de acciones punibles contra la administración pública. Entre ellos destacan de modo no exhaustivo- algunos de los siguientes: (i) soborno a funcionarios públicos nacionales y extranjeros, (ii) prevaricación, (iii) malversación, peculado, apropiación indebida de bienes o desvío indebido de recursos, (iii) tráfico de influencias, (iv) obstrucción de la justicia, (v) encubrimiento, (vi) blanqueo del producto de un delito. De aquí que la corrupción haya sido definida políticamente en términos muy amplios como "el uso indebido del poder público para fines privados" (Rose_Ackerman, 2008, p.55).

Hoy día la evidencia muestra que este fenómeno se halla en continuo aumento. De acuerdo con el Índice de Percepción de la Corrupción (IPC) 2017 de Transparencia Internacional, más del 66\% de los países evaluados obtuvieron en dicho rubro una calificación reprobatoria. Bajo un escenario como éste, no es de extrañar que la investigación tienda cada vez más a focalizarse en el estudio de las causas, consecuencias y posibles estrategias de combate contra este cáncer social que carcome a las naciones.

A la hora de abordar este asunto, espontáneamente tendemos a pensar el problema de la corrupción en términos de una preocupación por la incidencia que éste pueda tener en el socavamiento de las instituciones democráticas. Sin embargo, debemos plantear esta cuestión también en su sentido inverso, es decir: ¿cómo afecta o incide la democracia en las prácticas corruptas? Hay amplios estudios al respecto. Y aquí los resultados distan mucho de ser conclusivos. Unos afirman que la democracia es una poderosa herramienta para combatir la corrupción (Langseth, 1999, pp.12-15); (Treisman, 2000); (Chowdhury, 2004, p.13). Otros, por el contrario, prueban que las prácticas democráticas no muestran especial eficacia a la hora de garantizar ejercicios de poder limpios y transparentes (Kubbe, 2015); (Montinola y Jacman, 2002); (Olteanu, 2012). Algunos más, incluso, niegan que exista conexión alguna entre ambas variables (Fisman y Gatti, 2002, pp.336-338).

En conjunto estas investigaciones oscilan entre percepciones que intuitivamente tienden también a colisionar entre sí: por un lado, la competencia electoral debería ser un poderoso instrumento para sancionar a funcionarios corruptos y alejarlos del poder. Las autocracias, en contraste, dependen del apoyo de pequeños grupos como élites, burocracia estamento militar o policía secreta. Como resultado, 
la población tiene menos conocimiento de los procesos políticos y menos capacidad para influir en él, por tanto, sería de esperarse en ellas una transparencia deficiente y una débil rendición de cuentas. Lo cierto, empero, es que la realidad ofrece ejemplos claramente contrarios a esta intuición. Singapur es uno de los casos que típicamente suelen aducirse para corroborar esto: una ciudad, en definitiva, escasamente democrática, pero con niveles de corrupción prácticamente nulos.

Por otro lado, sucede que en democracia la necesidad de financiar las campañas políticas es un eficaz caldo de cultivo para que surja la corrupción. Incluso en democracias robustas y bien consolidadas la dependencia que el poder político tiene del económico con el fin de lograr financiarse, ofrece a grupos de interés y poderes oligárquicos la oportunidad de capturar las instituciones estatales para ponerlas a su servicio. Además, y como es bien sabido, el sistema representativo adolece de fuertes problemas de agencia: en términos de las teorías económicas del Agente-Principal y el mercadeo, si el gobernante es un delegado (o agente) cuya función es gestionar los intereses del principal (es decir, el electorado que lo elige), el contexto predominante en democracia es uno en donde existe asimetría de información entre agente y principal (el primero dispone de información que el segundo no tiene, y los costos de informarse para este último siempre son excesivos). Como agravante, el agente no tiene que sufrir ni padecer las consecuencias de sus propias decisiones, lo cual provoca que carezca de incentivos para decidir conforme a los intereses del principal ${ }^{1}$. Presumiblemente, ceteris paribus, el principal no ejercerá en realidad ningún control efectivo y vertical de rendición de cuentas sobre el gobierno. Como puede verse, entonces, en realidad no podemos hablar de razones a priori que permitan establecer si la democracia resulta o no más efectiva que la autocracia para abatir la corrupción.

El verdadero problema para determinar la relación entre ambas variables (corrupción y democracia) se halla, sin embargo, en otra parte. Estimar el efecto real de la democracia sobre la corrupción resulta complicado porque democracia y corrupción son variables endógenas (Kolstad y Wiig, 2011). Significa esto que su comportamiento suele estar mutuamente condicionado y verse, además, determinado a su vez por su relación con terceras variables omitidas o no observadas dentro del modelo político en que interactúan. Por ejemplo: decimos que el precio es endógeno a la demanda porque los precios se fijan en función de ésta, pero también los consumidores cambian su demanda en respuesta a los precios. Simultáneamente ambas cosas (demanda y precios) se encuentran afectados por una tercera variable: la oferta. De manera análoga: democracia y corrupción pueden verse afectadas por variables que resulten difíciles de observar o de cuantificar, como por ejemplo causas geográficas, históricas o culturales (en seguida

1 Para un análisis detallado sobre las teoría económica del Agente-Principal, véase (Gorbaneff, 2003, pp.75-86) 
me detendré en explicar esto). Paralelamente una democracia de bajo perfil o no consolidada puede estimular prácticas corruptas, al mismo tiempo que las prácticas corruptas con seguridad impiden que la democracia se consolide. Esto definiría una relación lineal negativa entre ambas variables, es decir, una relación en donde observamos que a mayor consolidación democrática habrá menor corrupción y a mayor corrupción habrá menor consolidación democrática. A menudo sin duda es así. Sin embargo, he dicho ya también que el vínculo endógeno entre estas dos variables no siempre obedece a esta lógica. Ello sucede, por ejemplo, cuando aun en democracias avanzadas las élites económicas capturan y se hacen del control de los procesos políticos.

Cualquier estudio serio sobre democracia y corrupción debe empezar, entonces, por reconocer este factor esencial de endogeneidad. En este texto defiendo la idea de que México es uno de los casos que más claramente ilustran el carácter endógeno entre democracia y corrupción. Para probar esto voy a proceder en tres pasos: (i) explicaré cuáles son las variables independientes, esencialmente de tipo histórico e institucional, que plausiblemente puede señalarse han incidido tanto en la generación de corrupción como en el diseño de la democracia mexicana (y en general también de casi todas las latinoamericanas). Se trata - como se verá- de variables que un estudio teórico como éste puede identificar, aunque su medición o cuantificación corresponde a un estudio empírico cuyo alcance por lo pronto rebasa los propósitos de este ensayo. Aquí me propongo simplemente trazar las hipótesis teóricas que prueban el carácter endógeno entre corrupción y democracia. En segundo lugar (ii), mostraré el impacto de estos procesos en la configuración institucional de México. Tal configuración explica que la apertura democrática que en el año 2000 puso fin al régimen de partido único de Estado (dando lugar a la alternancia política), detonara un incremento descontrolado en la corrupción, a la vez que esta escalada de corrupción ha impedido que la democracia se consolide. Finalmente, (iii), concluiré resumiendo muy brevemente cuáles son los elementos regulatorios y jurídicos que habrían de darse para que este círculo endógeno pudiera romperse.

\section{Corrupción: instituciones extractivas y colonización}

La aparición, hace solo algunos años del libro clásico Why Nations Fail? (Acemoglu y Robinson, 2012), ha sido una de las más importantes contribuciones dirigidas a mostrar y explicar las relación endógena que rige el vínculo entre instituciones políticas e instituciones económicas, o lo que es lo mismo, entre democracia - como régimen político-y corrupción —como forma distorsionada de comportamiento económico-.

La hipótesis central del libro de los profesores de MIT y Harvard es que el éxito económico o político de los países diverge debido a las diferencias entre sus 
instituciones, a las reglas que influyen en cómo funciona la economía y —de manera decisiva - a los incentivos que moldean y motivan la conducta de las personas. Con esto, Acemoglu y Robinson se distancian y critican hipótesis que tradicionalmente habían localizado la explicación sobre el fracaso o el éxito de las naciones en variables de tipo geográfico (Diamond, 1997), o cultural (Weber, [1930] 2002).

Diamond, por ejemplo, había atribuido en su obra clásica Germs, Guns and Still (1997) la prosperidad y dominio histórico del continente Euroasiático sobre África y América a la distribución de los ejes de estos continentes. Mientras que el eje principal del primero es horizontal-Este/Oeste (lo cual ancestralmente habría favorecido que ahí se propagaran más fácilmente semillas y animales domesticados, ideas y descubrimientos científicos, tanto como el trasiego de gérmenes homologando la capacidad de resistencia a las enfermedades entre pobladores), la orientación de los dos últimos es vertical-Norte/Sur. En una distribución Este/ Oeste hay regímenes similares de clima y temperatura pues en largas distancias no hay cambio de altitud, mientras que en una Norte/Sur los tipos de hábitat difieren tan enormemente (aun en unos cuantos kilómetros) que antiguamente esto dificultó la propagación de semillas aclimatadas, movilización de poblaciones, tecnología y gérmenes. Una semilla domesticada en un clima determinado podía fácilmente trasladarse miles de kilómetros por una misma latitud, pero no a través de altitudes distintas. Lo mismo puede decirse del desplazamiento entre virus o poblaciones. De ahí que el eje este-oeste de Eurasia permitiera que los cultivos (grupos humanos, gérmenes y/o descubrimientos tecnológicos como la escritura) viajaran rápidamente en franjas igualmente templadas de latitud. De este modo, el descubrimiento de la escritura se propagó rápidamente desde el Creciente Fértil a toda Mesopotamia, Asía y sur de Europa. En cambio, aun cuando la distancia entre el extremo sur de Mesoamérica y Perú es similar a la que separa los Balcanes de Mesopotamia, resulta revelador que los pueblos mesoamericanos poseyeran escritura y que este adelanto no llegara nunca al Imperio Inca — pues si bien éste contó con un sofisticado sistema de cuerdas y nudos para llevar cuentas y registrar archivos, no desarrolló jamás la escritura propiamente dicha-. También esta distribución en los ejes explica la razón por la cual los pueblos aborígenes de América carecían de anticuerpos para las enfermedades que portaban los españoles.

Del otro lado, por el ángulo de la hipótesis cultural, Weber concede enorme peso a factores sociales - como la religión - en el desarrollo de los pueblos. Así, encuentra que la economía y los procesos rápidos de industrialización florecieron en Inglaterra y los Países Bajos debido esencialmente a que el tipo de conducta requerido por el incipiente capitalismo era producto de la ética laboral protestante. Mientras que los países protestantes se adentraron rápidamente en la economía capitalista, la Europa católica seguía permaneciendo esencialmente feudal. Y es que la ética protestante, a diferencia de la católica, no condenaba la riqueza sino que la valoraba como indicador del favor divino y - junto a la ética pietista 
kantiana- prescribía al trabajador cumplir con su deber por el deber mismo. De ahí que, según Weber, el protestantismo fuera un factor cultural de enorme peso en el desarrollo del capitalismo y se aviniera mucho mejor a las exigencias de la industrialización temprana de lo que podía hacerlo el catolicismo.

Acemoglu y Robinson rechazan, no obstante, tanto la tesis geográfica como la cultural. En su opinión la hipótesis geográfica no aclara las diferencias de desarrollo entre, por ejemplo, la frontera norte de México y la frontera sur de Estados Unidos. De manera similar, la hipótesis cultural no explica tampoco el enorme diferencial -medido igualmente en términos de desarrollo- entre países que comparten una idéntica cultura (como las dos Alemanias antes de la caída del muro de Berlín) o, de modo más reciente, Corea del Norte y Corea del Sur. Esto les lleva a concentrar su análisis en la variable que consideran mucho más esencial: la variable institucional.

Son las instituciones de un país la variable fundamental que permite explicar su índice de desarrollo. Y según Acemoglu y Robinson éstas pueden ser dos tipos: inclusivas o extractivas. Las instituciones económicas inclusivas concentran institucionalmente el poder político. Al mismo tiempo son plurales, regulan y permiten la participación de diversos agentes en los procesos de producción, intercambio y generación de bienes y ganancias. Su característica principal es que ofrecen garantías de propiedad y reglas claras de competencia, operan bajo sistemas jurídicos imparciales que proporcionan igualdad de condiciones en las que las personas pueden realizar intercambios, firmar contratos, y contar con iguales costos de entrada. Esto da lugar a un entorno social (como Hayek lo ha descrito) al interior del cual la implementación de reglas formales e informales, así como su interpretación y aplicación, opera de manera consistente y predecible a través de un sistema de derecho eficiente y eficaz respaldado en un consenso social más o menos amplio (Hayek, 1973). Las instituciones extractivas, en cambio, son el resultado del fallo en cualquiera de estas condiciones. En caso extremo operan expropiando recursos de la mayoría, levantando barreras de entrada y suprimiendo el funcionamiento de mercados competitivos con el objeto de beneficiar a un reducido número de personas. Cuando esto sucede en economías de mercado, a tal fenómeno se le ha dado en llamar: "crony capitalism".

Esto hace que Acemoglu y Robinson encuentren una estrecha relación endógena entre régimen político (democrático o no, inclusivo o no) y régimen económico. En sus palabras:

Existe una fuerte sinergia entre las instituciones económicas y las políticas. Las instituciones políticas extractivas concentran el poder en manos de una élite reducida y fijan pocos límites al ejercicio de su poder. [A la vez] las instituciones económicas a menudo están estructuradas por esta élite para extraer recursos del resto de la sociedad. Por lo tanto, 
las instituciones económicas extractivas acompañan de forma natural a las instituciones políticas extractivas. De hecho, deben depender inherentemente las unas de las otras (Acemoglu y Robinson, 2012, p.103).

Esta relación sinérgica entre instituciones políticas y económicas introduce lo que igualmente ellos llaman "un bucle de fuerte retroalimentación" entre el comportamiento de los agentes dentro del mercado y las reglas políticas que regulan su interacción (Acemoglu y Robinson, 2012, p.104). Las instituciones políticas y los sistemas normativos que ellas imponen forjan las bases que definen la operación de las instituciones económicas. A su vez, éstas estructuran el futuro de las instituciones políticas y su evolución. En otras palabras, instituciones económicas inclusivas requieren establecerse sobre la base de instituciones políticas igualmente inclusivas. Éstas también dificultan que grupos o élites socaven los fundamentos del poder público para ponerlo al servicio de fines privados (lo que al inicio de estas líneas definimos precisamente como "corrupción"). Así pues, en esto consiste el bucle endógeno de retroalimentación: instituciones económicas extractivas enriquecen a élites que luego utilizan su poder económico para consolidar indebidamente el dominio político que les favorece. No es probable que instituciones económicas extractivas sobrevivan bajo instituciones políticas inclusivas e inversa. "Los países fracasan cuando tienen instituciones económicas extractivas, apoyadas por instituciones políticas igualmente extractivas que impiden [...] el crecimiento económico y generan corrupción" (Acemoglu y Robinson, 2012, p.106).

La cuestión central que de inmediato surge, entonces, es: ¿por qué las políticas de algunas sociedades conducen a instituciones inclusivas que fomentan el desarrollo, mientras que las políticas de otras conducen a instituciones extractivas que lo dificultan? Los propios Acemoglu y Robinson ofrecen una respuesta. Permítaseme resumirla.

Dijimos en la introducción que hay una relación endógena cuando dos variables se condicionan recíprocamente, pero también cuando ambas ven determinado su comportamiento por su relación con terceras variables omitidas o no observadas dentro del modelo político en que interactúan. En este caso, comportamiento político y económico se configuran mutuamente entre sí, pero dar una respuesta completa a la pregunta que hemos planteado acerca del origen de las instituciones (extractivas o inclusivas) obliga, a la vez, a rastrear los factores determinantes que moldean el comportamiento político y económico en causas que afectan por igual a ambas. Estas causas esencialmente son de tipo histórico. En el caso particular de México, pero en general en toda América Latina, no es posible entender el comportamiento actual de las instituciones sin remontarse a su origen histórico y al modelo de colonización desde el cual aquéllas han emergido.

Existe una diferencia esencial entre el modelo de colonización que España siguió en América y el que, por ejemplo, Inglaterra se vio forzada a implementar 
en los Estados Unidos (Acemoglu y Robinson, 2012). La estrategia de colonización española fue muy efectiva y esencialmente se basó en la observación y comprensión detallada de las sociedades precolombinas. Dentro de su enorme complejidad, estas sociedades se estructuraban a partir de férreos sistemas de poder vertical. Basándose en esta observación los españoles se percataron de que la mejor forma de dominar al adversario era aprehender al líder indígena. Los dos más grandes imperios prehispánicos fueron desarticulados siguiendo exactamente el mismo guion: capturar al emperador, reclamar la riqueza acumulada de los líderes y luego coaccionar a los pueblos para, a cambio de respetar la vida de sus dirigentes, forzarlos a entregar tributos y comida. El paso siguiente consistió en que españoles se establecieran como la nueva élite de la sociedad indígena y conservar los fueros de los estamentos gremiales con la condición de hacerse del control de los impuestos y tributos ya existentes y el control de los trabajos forzados. Aunada a una hábil política de alianzas con los pueblos enemigos de los aztecas, tal fue la estrategia que siguió Hernán Cortés al ser recibido junto a sus tropas por el emperador Moctezuma en noviembre de 1519 en Tenochtitlán (lo cual le permitió capturar al emperador en su propio palacio), y tal fue la estrategia que siguió Pizarro el 15 de noviembre de 1532 cuando, después de tenderle una trampa y matar a sus guardias y criados, los hispanos capturaron al emperador Inca Atahualpa en Cajamarca. Consolidada la conquista, los españoles impusieron en América un modelo político-económico de instituciones netamente extractivas. La institución extractiva por excelencia fue la encomienda: una cesión de indígenas a un español que recibía el nombre de encomendero, los cuales trabajaban para él y le pagaban tributo. El modelo análogo en Perú fue la mita. El sistema de la mita (especialmente en ciudades mineras como Potosí) llegaría a convertirse en uno de los esquemas más grandes de explotación y mano de obra que permitió enriquecerse a los españoles a costa de la pobreza de los pueblos.

Acemoglu y Robinson explican que los primeros colonos ingleses intentaron ensayar en Carolina del Norte un modelo de coloniaje similar al español basado en la institucionalidad extractiva. Sin embargo, el resultado fue un rotundo fracaso. Muy pocos años después los británicos volvieron a intentarlo en Virginia al fundar el asentamiento de Jamestown. Su modelo de colonización estaba fuertemente influenciado por el que años antes habían seguido Cortés y Pizarrro: capturar al jefe local y luego utilizarlo para obligar a la población a trabajar para extraer recursos para ellos. Sin embargo no contaban con algo: como lo ha documentado la antropología política de Pierre Clastres (1983), el modelo de autoridad de aquellos pueblos era muy distinto al mesoamericano. El régimen de poder era mucho más horizontal que vertical por lo que capturar a los jefes no rendía ni desorientaba a los súbditos, además de que, a diferencia de Incas y Aztecas, los pueblos de Virginia no tenían oro (contrasta significativamente con Moctezuma y Atahualpa la respuesta que el jefe del imperio Powhatan Wahunsunacock ofreció a Jamestown, cuando éste lo invito a homenajearlo en 
nombre de Carlos I: "si tu rey quiere verme yo no voy a morder ese anzuelo y arriesgarme a ser capturado. Yo también soy rey, y ésta es mi tierra”) (Acemoglu y Robinson, 2012, p.37).

Pese a todo esto, la empresa que financiaba la colonización —Virginia Company - no desistió. Si los pueblos indígenas no podían ser explotados —razonó la empresa - tal vez los colonos sí. Bajo este nuevo proyecto la Virgina Company impuso una serie de medidas verdaderamente draconianas: la empresa sería la dueña de las tierras. Los hombres vivirían en barrancones y recibirían porciones raquíticas de alimento de mera sobrevivencia. Cada barrancón tendría un supervisor o capataz durante toda la jornada de trabajo. Cualquiera que pretendiera huir del asentamiento sería castigado con la pena de muerte.

El resultado de tales medidas nuevamente derivó en un fracaso rotundo aun peor que el anterior: los colonos huyeron masivamente. Los pocos que quedaron se negaron a trabajar. Así, a partir de 1618, la Virginia Company se vio forzada a adoptar una estrategia de colonización enteramente distinta. Dado que no era posible forzar a los colonos a trabajar para los dueños (ni tampoco a los indígenas) se decidió ensayar un ambicioso programa de incentivos. El célebre filósofo inglés John Locke contribuyó a redactar las nuevas ordenanzas: se instituyó un sistema de reparto de tierras por cabeza, se garantizó la propiedad privada y el derecho al usufructo del propio trabajo. Los colonos recibieron casas y fueron liberados de sus contratos. De modo más relevante: las nuevas instituciones inclusivas que surgieron por la necesidad de garantizar la viabilidad económica de la colonia, pronto dieron lugar a que los residentes en ellas se mostraran dispuestos a invertir y trabajar duro solo si estos cambios se instituían de la mano de prerrogativas políticas que les garantizaran no perder sus derechos y condiciones. Como consecuencia, en 1619 se introdujo una Asamblea General que daba voz y voto efectivo a todos los hombres propietarios para decidir sobre las leyes e instituciones que regirían en la colonia. Esto sentó las bases del inicio de la democracia en Estados Unidos. Una democracia de pesos y contrapesos, así como de regulaciones inclusivas acorde con el funcionamiento de las instituciones económicas inclusivas de la colonia.

Por tanto, ambos modelos de colonización (el español y el británico) dieron lugar a dos modelos de desarrollo muy distintos. Al dispersar el poder entre agentes que se limitan entre sí (aunque sin dejar de centralizarlo política o estatalmente), un régimen inclusivo obstaculiza la corrupción. Al concentrarlo en pocas manos (o dispersarlo en muchas, pero sin centralización política ni control estatal), un régimen extractivo inevitablemente la genera. Como resultado del modelo institucional extractivo impuesto en los virreinatos españoles, en 1690 tenemos ya noticias de claras expresiones de indignación dirigidas por la Real Audiencia de México al Consejo de Indias protestando por "un rumor de venta de cargos públicos en la colonia” (García-García, 20016, 133). 
Es bien sabido que el fenómeno de la venta de cargos y oficios públicos fue de hecho un fenómeno generalizado durante la Monarquía Hispánica de los Austria. Se dio en todos sus territorios, desde Castilla hasta los dominios de ultramar. Incluso terminó convirtiéndose en un recurso fundamental de la Hacienda Real. Como es claro, esto supuso la generalizada corrupción del sistema administrativo de los Austria (que posteriormente intentarían con deficiencia corregir las reformas borbónicas). Este fenómeno de venta de cargos y oficios públicos jamás podría haberse dado en el modelo inclusivo adoptado en Virginia. Por las razones que he descrito, los colonos jamás lo habrían aceptado. En cambio tenía pleno sentido en el seno de la institucionalidad extractiva hispana: éste permitía (e incluso exigía) el uso del poder público para enriquecerse. De ahí que los grupos más poderosos incorporaran en sus mayorazgos cargos importantes como escribanías, cargos municipales (regidores, alguaciles, jurados) así como puestos recaudatorios y fiscales (contadores y receptores). La Hacienda Real necesitaba ofertar estos oficios y cargos para financiarse, tanto mediante venta directa para vacantes de nueva creación como en concesión perpetua (o hereditaria). La Real Cédula de 1606 establece ya el derecho de una persona que había comprado un oficio a heredarlo a perpetuidad (García-García, 2016). Esto supone y define el paradigma del modelo extractivo descrito por Acemoglu y Robinson. Aún más claramente, exhibe la correlación sustancial y necesaria entre instituciones extractivas y corrupción: la venta de cargos públicos para enriquecimiento privado (el uso del poder público para fines privados) es, pues, consustancial al modelo extractivo que emerge de la conquista. En 1740 una Real Cédula de Felipe V incluso sanciona el derecho a la retroventa de estos cargos, y el derecho a usar de ellos hasta que el comprador recuperara cuando menos el monto de lo invertido. Oficios públicos enajenados generan un Estado débil, sin control ni poder centralizado, con nula capacidad de sanción, e impotente de cumplir ninguna función regulatoria para interceder de modo imparcial y oportuno entre intereses en pugna. Dije en la introducción que no es posible entender el fenómeno de corrupción en América Latina si éste no se vincula a las variables institucionales e históricas que aquí he descrito. Ahora resta por explicar cómo esta historia institucional conecta con el origen de la democracia mexicana durante el periodo de partido único de Estado que prevaleció en ese país entre 1928-2000, y por qué el proceso que puso fin a este régimen en el año 2000 dio lugar a una nueva forma de corrupción aún más descontrolada y generalizada.

\section{México: corporativismo, democracia y corrupción}

El universo extractivo es un mundo de castas y privilegios: se basa en el dominio de unos pocos sobre los muchos. Esto resulta especialmente claro en la institucionalidad corporativa que emerge de la colonia. En México, el periodo posterior a la 
captura final de Tenochtitlán en agosto de 1521 no puso fin a la guerra. Ésta aún se extendió al reino de Michoacán y otros señoríos del centro y sur del país cuya conquista definitiva no se dio sino hasta 1526. El resultado final de este proceso fue el establecimiento de una relación formal de dominio entre los españoles y cada uno de los señoríos en términos en los que, al mismo tiempo que se permitió a cada comunidad conservar su antigua forma de gestión, autoridad y capacidad de recabar impuestos, los señoríos accedían a entregar a su encomendero parte sustantiva de sus recursos como tributo. La conservación de los señoríos fue pieza clave del gobierno local, del sistema tributario y de la evangelización. A los señoríos les fue impuesta una organización corporativa inspirada en los cabildos castellanos, y su función también era inducir y presionar para que los pueblos indios comenzaran a congregarse en asentamientos urbanos. Este sistema corporativo mediante el cual el poder hispano se garantizaba la adhesión de los señoríos incorporándolos al esquema de gobierno, es la puerta de entrada que dio inicio al sistema institucional que prevalecería en México desde la colonia, la Revolución mexicana de 1910, y el régimen de partido único que emergió del proceso revolucionario. Es este régimen el que formalmente organizó de manera hegemónica la vida institucional del país entre 1928 y el año 2000 (Curcó, 2010, pp.63-67).

Los rasgos corporativos del régimen virreinal aparecen posteriormente de modo más nítido en el México posrevolucionario que sienta las bases del Estado moderno. Fue el obregonismo, esencialmente, la primera corriente revolucionaria que ya en pleno siglo XX supo que la consolidación de un gobierno burgués no podía fincarse enfrentando directamente a las masas campesinas y obreras, sino que exigía la subordinación de estos grupos haciéndoles concesiones, controlándolos desde arriba y al mismo tiempo apoyándose en ellos para someter a cualquier fuerza que desafiara al nuevo poder hegemónico. Quince años después, en el llamado segundo ascenso de la revolución, el cardenismo en México consolidará aún más este régimen corporativo, haciendo que un conglomerado industrial todavía en extremo débil y un poder centralizado en proceso de afianzarse se orientaran abiertamente a incorporar al esquema institucional a mayor número de sindicatos, organizaciones campesinas civiles, obreras y de estudiantes a cambio de prebendas. Poco a poco, es esto lo que acabará definiendo el Estado corporativo mexicano del siglo XX, y que, en términos de Phillipe Scmitter podemos resumir así:

[Estado corporativo] es un sistema de representación de intereses en donde las unidades constituyentes están [...] jerárquicamente organizadas y funcionalmente diferenciadas, reconocidas o autorizadas (si no creadas) por el Estado mismo, y a las que se les otorga un monopolio representacional dentro de sus respectivas categorías a cambio de la observación de ciertos controles en la selección de sus líderes y en la articulación de sus demandas y apoyos. (Schmitter, 1994, pp.93-94). 
Schmitter hace además una importante diferenciación entre corporativismo social y corporativismo estatal. El primero implica un robustecimiento más o menos autónomo de la sociedad frente al poder político, a través de organizaciones que amplían la acción colectiva dotando a ésta de capacidad para concertar y negociar con la autoridad pública. El corporativismo estatal, en cambio, difiere del anterior en que aquí no es la sociedad la que se organiza para forzar al Estado a reconocer a las organizaciones el monopolio de la representación que ostentan, sino que más bien es el Estado quien genera las organizaciones con el objeto de ejercer control sobre ellas y mantenerlas bajo su dominio. Mientras que en el primer caso el corporativismo activa y amplía la acción colectiva, en el segundo, por el contrario, éste se dirige a contener y "encapsular" la presión social (Schmitter y Lehmbruch, 1992). Esto es relevante para el caso de México, pues a diferencia del corporativismo social de Austria donde los acuerdos entre colectivos y dirigencia estatal son reflejo institucionalizado de la correlación de fuerzas entre demandas sociales y poder central, el tipo de corporativismo que en México consolidaron los primeros regímenes posrevolucionarios fue de tipo claramente estatal: "la función del corporativismo mexicano desde sus orígenes fue restar autonomía al dinamismo político frente al Estado, conteniendo la "extrema vitalidad social" (Bizberg, 1990, 698). El historiador Adolfo Gilly ha expuesto en su libro clásico La revolución interrumpida las razones de origen que dieron lugar a esto: la Revolución Mexicana aconteció en el inicio de un muy incipiente capitalismo en el que las clases burguesas lograron apropiarse de las demandas obreras y campesinas incorporándolas a su proyecto de nación. Sin embargo esta incorporación buscaba contener, antes que promover, las exigencias populares: el objetivo de desarrollar una nueva burguesía "no podía lograrse enfrentando directamente a las masas, sino que necesitaba contenerlas haciéndoles concesiones controlándolas desde arriba y al mismo tiempo apoyándose en ellas" (Gilly 1971, 338-339).

Esto último es importante, pues si bien superficialmente podía parecer que un corporativismo estatal es fuerte en la media en que logra someter hegemónicamente a aquellos grupos que representan un desafío, la realidad es que un Estado corporativo a la larga siempre termina por exhibir vulnerabilidad y debilidad. La razón de ello es clara: al experimentar la necesidad de apoyarse en corporativos para afianzar su control hegemónico, el Estado termina a la larga por depender en extremo de su estructura clientelar.

Esto es un dato clave: al corporativismo estatal le es inherente un Estado clientelar. Entiendo por clientelismo la acción gubernamental —si el agente está en el poder - o social - si no lo está - dirigida a entregar bienes o servicios a grupos políticamente cautivos (o clientelas) a cambio de lealtades que no derivan del legítimo juego democrático ni de aquello estrictamente establecido por la ley. En este sentido, el clientelismo es consustancial a la corrupción: significa un intercambio deshonesto de lealtades y favores, una manera de hacer política y gestionar el poder 
que requiere el constante desvío de fondos públicos para satisfacer intereses privados. Como consecuencia de esto un Estado clientelar-corporativista es fácilmente víctima del chantaje: un Estado débil. De modo más significativo, un Estado con estas características no dispone de sus excedentes pues permanentemente se ve forzado a destinar sus recursos para cooptar a los grupos de interés que lo apuntalan. En tales condiciones deja de haber obra pública. La inversión no se dirige a generar desarrollo, empleo, competitividad, innovación e infraestructura, sino que ésta se encamina a financiar el subdesarrollo dilapidando los recursos en pago a élites y grupos corruptos. Esto hace de México un paradigma de Estado corporativo-clientelar atrapado en una lógica venal y perversa de financiación al subdesarrollo. Basta para ilustrarlo un solo ejemplo: según datos del Instituto Mexicano para la Competitividad (IMCO), los excedentes presupuestales que se transfirieron a estados y municipios entre 2006 y 2008 -durante los gobiernos que emergieron de la primera alternancia democrática en la historia del país - representaron en términos reales (es decir, una vez ajustadas las cantidades a tipo de cambio e inflación), más del 56\% de la totalidad de recursos que al final de la Segunda Guerra el plan Marshall destinó para la reconstrucción de Europa. Significa que, en solo dos años, parte de los excedentes de México superaron por mucho el costo de la reconstrucción de todo un continente. No obstante ello, esos recursos no se invierten en nada productivo, sino que están destinados únicamente a financiar gasto corriente y corrupción.

El resultado de todo esto es un Estado consustancialmente corrupto. Esta corrupción endógena, no obstante, es en realidad producto de las variables y desarrollo histórico que - de acuerdo al apretado resumen que he hecho - tienen su origen en una institucionalidad extractiva. Con lo dicho hasta aquí tal vez podría argumentarse que he remontado el origen de estas variables a las épocas coloniales, revolucionaria y postrevolucionaria del régimen mexicano, es decir, a los periodos en los que en éste país no existió democracia. Pero el año 2000 supuso para México la finalización de un régimen hegemónico de partido único de Estado que se había mantenido en el poder desde 1928. Al inicio del nuevo siglo esto cambió. A partir del año 2000 y hasta el 2018 en México se ha dado una alternancia dinámica de gobiernos. A dos periodos consecutivos de gobiernos conservadores de derecha siguió un nuevo periodo de gobierno del otrora partido único (PRI). Posteriormente, en 2018, el Movimiento de Regeneración Nacional (MORENA) ha tenido un triunfo aplastante en las urnas, lo que por vez primera ha significado que el centro izquierda se haga del poder federal y el control de ambas cámaras. Si atendemos a la definición minimalista de Przeworski según la cual "democracia es un régimen donde los partidos de gobierno pierden elecciones" ${ }^{2}$, no hay duda

2 Przeworski, Adam. Entrevista. Disponible, en: https://www.enperspectiva.net/en-perspectiva-programa/entrevistas/ politologo-adam-przeworski-la-democracia-no-es-algo-que-se-tenga-que-definir-en-terminos-estandares-para-todoel-mundo/ [Consultado enero 2019] 
de que México ha consolidado de manera clara al menos una democracia de tipo electoral.

Sin embargo, los datos muestran que siendo México - por las razones ya descritas- un Estado clientelar, la consolidación democrática ha tenido como efecto disparar a niveles nunca antes visto los indicadores que miden la variable de corrupción. Los datos al respecto son abrumadores: según el Î́ndice de Impunidad Global, México es hoy - después de Filipinas- el segundo país con mayor impunidad en todo el mundo. La tasa de impunidad en México es del 99.3\%, al mismo tiempo, esta nación padece uno de los más severos problemas de corrupción en el planeta. De acuerdo al índice de Percepción de la Corrupción de Transparencia Internacional, México ocupa el lugar 135 de 180 naciones evaluadas. En los últimos 15 años el país ha reprobado sistemáticamente las mediciones de este índice (con calificaciones que han ido del 3.3 al 3.7 en una escala del 1 al 10). Es el lugar 12 de 15 en América Latina en materia de sobornos. Según el barómetro de las Américas casi ocho de cada diez mexicanos consideran a México un país con altísimos niveles de corrupción. ¿Cómo puede ser esto posible? ¿Por qué razón en México más democracia ha significado una mucha mayor impunidad y corrupción?

Se trata de una cuestión que apenas recientemente la literatura ha comenzado a estudiar y comprender. Pioneros en este análisis (de tipo multidisciplinar) lo han sido Luis Astorga (2010), desde la perspectiva socio-histórica, y Luis Carlos Ugalde (2015) desde la perspectiva electoral. Ambos mantienen interesantes tesis cuyo sentido conecta directamente con todo lo que hasta aquí hemos visto. Permítaseme explicarlo a continuación.

Dijimos que una intuición asociada a la relación endógena entre corrupción y democracia es que a mayor democracia debería haber menos corrupción. Pero también vimos que esto es así solo cuando hablamos de regímenes económicos y políticos de corte inclusivo (e instituciones inclusivas pueden darse tanto en autocracias como en democracias). Como Acemoglu y Robinson exponen, las instituciones inclusivas incorporan a distintos agentes a través de un entramado de pesos y contrapesos, incentivos y regulaciones claras y predecibles con sanciones y garantías políticas de participación. Sin embargo, debido a las causas históricas que repasamos, las instituciones en México adolecen de un origen y un sentido netamente extractivo. Instituciones extractivas suponen élites depredadoras que imponen reglas discrecionales y ejercen el poder sin control. El régimen corporativista y de partido único de Estado pudo operar durante años sin controles políticos, administrativos y patrimoniales. Careció igualmente de un sistema mínimamente efectivo de rendición de cuentas con premios y castigos para los actores y las instituciones que actúan en el ámbito público. La tesis central de Astorga (que aquí plenamente suscribo) es que la única razón por la que el régimen pudo operar bajo tales condiciones fue porque, en medio de ellas, siempre mantuvo la centralización corporativa y vertical del poder y la autoridad (Astorga, 2010). 
Según Acemoglu y Robinson, por ejemplo, ésta es una diferencia esencial entre un país como México y otro como Somalia. Ambas son naciones que se erigen sobre la base de instituciones meramente extractivas, sin embargo, la primera logró durante buena parte de su historia una centralización política y estatal del poder, algo que en Somalia la pugna y férrea división entre clanes siempre impidió (Acemoglu y Robinson, 2012, pp.102-103).

Ciertamente en México el régimen de partido único de gobierno logró centralizar - al menos en alguna media- la gestión de la corrupción y la delincuencia. En palabras de Ugalde, instituyó "un proceso jerarquizado de corrupción política que ponía en la voluntad del Ejecutivo la cantidad y magnitud de negocios que se podían hacer al amparo del poder" (Ugalde, 2015, p.15). Este rasgo, característico por otra parte, de muchos de los regímenes que hemos denominado extractivos, aparea, sin embargo, un elemento claramente paradójico: la concentración del poder discrecional imponía ciertos límites a la discrecionalidad de otros agentes estatales para sobornar, corromper o cometer actos abiertamente delictivos. Suprimida esta concentración del poder, emergió, entonces, una corrupción mucho más dañina. Porque si la corrupción en México durante el siglo XX fue resultado del excesivo poder extractivo concentrado en la presidencia y el partido único de Estado (PRI), la corrupción que surge en el siglo XXI inevitablemente ha de ser entendida como "resultado de la dispersión del poder y de la apertura de muchas ventanillas" de oportunidad para realizar acciones delictivas (Ugalde, 2015, p.9). Es fácil entender a lo que Ugalde se refiere: instituciones extractivas significan ausencia total de controles regulatorios institucionales. Bajo tales circunstancias, el poder centralizado opera como único regulador discrecional. El derrumbe de este poder genera, entonces, que prive el descontrol completo. Regidores, congresos, gobernadores locales y presidentes municipales se vuelven reyezuelos locales capaces de operar bajo total impunidad. Recordar, además, que en México los sistemas de impartición de justicia se hallan literalmente feudalizados pues en México las fiscalías no gozan de independencia ni autonomía técnica, sino que funcionan siguiendo las órdenes de aquellos funcionarios a quienes deberían de supervisar y, en su caso, sancionar. Hasta el momento en que se escriben estas líneas, el artículo 102 constitucional y los ordenamientos jurídicos tanto estatales como federales, dificultan y entorpecen la posibilidad de contar con fiscales realmente autónomos que puedan ejercer sus funciones sin estar controlados por los poderes ejecutivos. La agenda para dotar de autonomía a los fiscales está aun en proceso y, hasta 2018 , no parece que vaya a cristalizar.

La conclusión es que el arribo del partido conservador de derecha al poder en el año 2000 que puso fin a más de 70 años de gobierno de partido único, implicó una transición democrática, pero de tipo fallido, pues dejó intacta la naturaleza extractiva del Estado. La llamada transición democrática en México no implicó en lo absoluto la introducción de un mínimo de controles regulativos, sino todo 
lo contrario. Los primeros diez años de régimen de transición política en el país dejaron sin tocar la estructura clientelar del Estado. El nuevo partido en el poder se acomodó pronto a la lógica venal y corporativa del intercambio corrupto de prebendas y canonjías, creó sus propias clientelas empresariales y sindicales, y continuó de manera agravada el desvío y la dilapidación millonaria de recursos en el pago de corruptelas. Aunado a esto, fue perdiendo la concentración vertical del uso del poder.

Esta desordenada descentralización del poder presidencial dejó huecos o vacíos de autoridad profundos. Municipios no vinculados a ningún proceso de rendición de cuentas, entidades federativas con sistemas judiciales feudales que no están sujetos a sistemas de vigilancia de sus decisiones, sindicatos corporativos solariegos y medievales, presencia de gobernadores y actores políticos que no tienen ya que someterse a ningún control patrimonial, vastas empresas del sector público infiltradas por grupos criminales que a la vez financian campañas electorales; todo esto da cuenta del escenario de baja gobernabilidad política que generó el contexto adecuado para que los grupos criminales encontraran las condiciones ideales que les permitieran emprender la captura total del Estado ${ }^{3}$.

El resultado de esta llamada "transición democrática" fue, entonces, un vacío completo de gobernabilidad y voluntad política que el experto José Luis Salazar Arévalo ha descrito en estos términos:

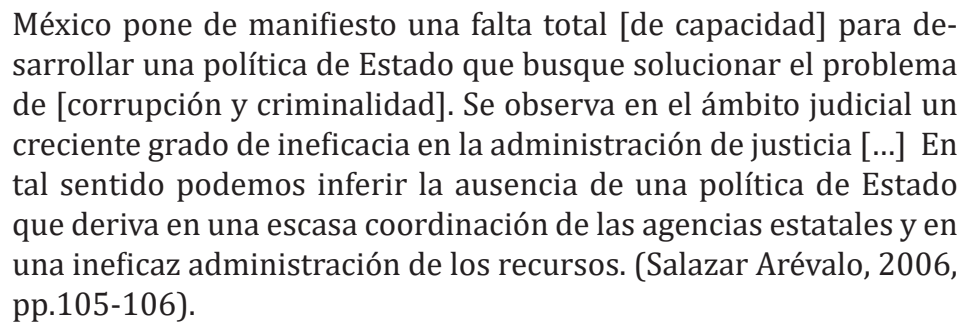

Lo señalado por Salazar tiene su origen en el régimen clientelar corporativista previo a la irrupción democrática. La llamada transición democrática en México dejó intacto ese régimen pero además, en palabras de Ugalde, al debilitar la centralización del poder político generó una "pulverización de los puntos de acceso para lucrar con la influencia política" (Ugalde, 2015, p.10). Diversos actores y jugadores políticos repentinamente ya no tuvieron que rendir cuentas a ninguna autoridad central, con lo cual, leyes, contratos, aplicación de justicia, permisos y presupuestos - tal y como ocurrió con la venta de puestos públicos durante la

3 Según datos de la Comisión de Desarrollo Municipal de la Cámara de Senadores, en 2010, 71\% de los municipios del país se hallaban ya bajo control total o parcial de las mafias. Véase Curcó $(2010,17)$. 
colonia- se volvieron patrimonio personal de funcionarios en un entramado institucional plenamente fragmentado.

El caso México es muy relevante, porque permite soportar una tesis que es fundamental: el control de la corrupción no está esencialmente vinculado a la consolidación democrática. Esto debido a que los controles democráticos son esencialmente de tipo vertical y solo resultan efectivos si el ciudadano (principal) invierte tiempo y esfuerzo en monitorear estrechamente al gobernante (agente). Tal tipo de controles - a menos que operen bajo una cultura vigorosamente cívica y un orden institucional de alto perfil-difícilmente logran superar los problemas de agencia ya mencionados antes. Estos controles, además, de nada sirven sino van precedidos por otros de tipo más bien horizontal, es decir, regulaciones de tipo legal y jurídico capaces de forzar a los agentes a operar conforme a los estándares de una institucionalidad inclusiva (véase, Casar, Marvan \& Puente, 2012, p.p.331-405). Cuando las fallas regulatorias son graves, la democracia, incluso, puede no hacer más que agravar el problema porque los vacíos de Estado inevitablemente siempre dan lugar a que emerjan agrupaciones de actores no estatales dispuestas no solo a capturar los procesos políticos, sino a disputarse con violencia y corrupción los vacíos que deja un Estado débil. Un dato desgarrador ilustra esto: en las elecciones federales de 2018 en México, más de 120 candidatos a puestos de elección fueron asesinados ${ }^{4}$ Conforme al informe de la Comisión de Desarrollo Municipal de la Cámara de Senadores, hace ocho años se tenía constancia de que 75\% de los municipios se hallaban ya bajo control total o parcial del crimen organizado. Lo que el caso México muestra, pues, es que los vacíos de poder institucional y la ausencia de un Estado que se comporte de manera consistente, predecible, coherente y legítima bajo férreos controles normativos, configuran la variable más estrechamente vinculada al descontrol de la impunidad y la corrupción.

\section{A modo de conclusión: controles normativos y combate a la corrupción}

Todo Estado y sociedad requieren poseer anticuerpos institucionales sólidos que prevengan los comportamientos corruptos y delictivos. Sin embargo, nunca ha ocurrido que élites político-empresariales de corte netamente extractivo se autoimpongan controles que limiten sus capacidades discrecionales para extraer ganancias y seguir ejerciendo el control. El desarrollo de la sociedad civil organizada es condición necesaria para que redes de contraloría social autónomas similares a las que han surgido en países como Chile, Colombia, Costa Rica o España, impulsen las medidas que permitan implementar mecanismos institucionales

4 CNN en español. Disponible en: https://cnnespanol.cnn.com/2018/06/25/mexico-violencia-campana-120-politicosasesinados/ [Consultado enero 2019] 
adecuados de regulación. En Canadá, por ejemplo, ocho de cada diez denuncias ligadas con la corrupción política provienen de redes de contraloría ciudadanas. Existen, además, paneles ciudadanos de monitoreo dirigidos a revisar cuáles son los resultados de las quejas que se interponen, así como el grado de satisfacción de los quejosos con la respuesta institucional (Buscaglia, 2013, p.35, p.73).

En este artículo he querido mostrar que, desde la época colonial, las instituciones de justicia en Latinoamérica fueron diseñadas más para responder a lealtades políticas que a la efectividad jurídica o la eficiencia punitiva. En México la consolidación de un régimen clientelar corporativo no vino más que agravar esto. Los ministerios públicos (o fiscales) siguen bajo el control total del poder ejecutivo tanto a nivel federal (presidente) como local (gobernadores). Estos últimos ejercen ominoso control autoritario en el nombramiento y permanencia de jueces, fiscales y jefes de policía. No hay controles técnicos-jurídicos de las resoluciones judiciales, ni servicio civil de carrera, profesionalización, o control legislativo sobre las actividades de los órganos de justicia a través de comisiones legislativas con apoyo de personal técnico de carrera.

He intentado hacer ver que esta situación es resultado de procesos históricos que han sido desastrosos, pues la criminalidad y la corrupción se alimentan de las fallas normativas de los Estados. A partir de este diagnóstico, es necesario, entonces, identificar los canales por los cuales los sistemas legales y judiciales que afectan el desarrollo de una nación pueden desarrollarse. Esto por sí solo sería materia de otro artículo, pero no quiero terminar sin antes dejar cuando menos apuntados los controles institucionales mínimos que Estado y sociedad civil habrían de institucionalizar con el fin de recomponer la grave situación que aquí he analizado. Edgardo Buscaglia (2013, p.28) uno de los más brillantes especialistas en el tema, los ha resumido del siguiente modo:

1. Controles judiciales. Tienen que ver con la capacidad del Estado para disuadir y sancionar los comportamientos antisociales en todos los niveles. Como mínimo, esto requiere sistemas de fiscalía absolutamente separadas del poder político y que gocen de autonomía técnica. La autonomía técnica debe tener como única limitante la ley y supone, a su vez, policía y procedimientos estandarizados y profesionalizados conforme a las prácticas científicas criminalísticas y técnicas de investigación apegadas al respeto al debido proceso.

2. Controles patrimoniales. La acción de la justicia ha de ser proactiva y no meramente reactiva. Para ello se necesitan unidades de inteligencia financiera en cada unidad local política y/o administrativa operando en red y de forma coordinada a nivel federal. Estos controles deben ser también técnicamente autónomos de los poderes ejecutivos y estar supervisados por comisiones especializadas de los poderes legislativos locales y federales. Además, deben dirigirse también a romper las concesiones monopólicas y oligopólicas, cuyo 
inicio tuvo origen también en la Colonia (Victoria \& Pérez, 2005). Debe entenderse que las fallas regulatorias que alimentan los oligopolios tienen dos efectos: (i) generan mercados concentrados de oferta que gravan esencialmente a los más pobres al impedir la competencia leal de servicios y precios, y (ii) constituyen una invitación a que grupos criminales cubran la demanda excedente de servicios o productos derivadas de los sobreprecios generados por quienes controlan el mercado.

3. Controles a la corrupción. Consisten en criterios de indagación judicial dirigidos a limitar la discrecionalidad de los poderes ejecutivos, legislativos y judiciales. Bajo un entramado institucional extractivo, estos tres poderes siempre generan círculos de impunidad política y económica a su alrededor. De ahí que los controles anti-corrupción sean esenciales para fijar la respuesta institucional a cualquiera de las violaciones que en la introducción expliqué componen el bolsón de delitos tipificados en los llamados "delitos de corrupción". En democracia, estos controles son indispensables para evitar que los procesos políticos sean capturados por grupos de interés y mafias, por ejemplo, indagando proactivamente el origen de los recursos económicos que ingresan en las campañas.

4. Controles sociales. Bajo el predominio de instituciones extractivas, solo estos mecanismos pueden inducir la aplicación de los tres controles anteriores. Están conformados por vastas redes de asociaciones civiles cuya difícil tarea no solo es monitorear de manera especializada el comportamiento de las instituciones públicas, sino trabajar a nivel de base social en todos los rincones del territorio donde el Estado no llega.

Con todo, el operar discrecional de élites extractivas obedece, como en su momento dejamos claro, a un bucle de retroalimentación originado en un acuerdo y un pacto de impunidad entre dichas élites, pues son ellas las únicas que se benefician de los vacíos institucionales y, por tanto, son esencialmente ellas las únicas interesadas en bloquear todo intento dirigido a fortalecer el Estado y someterlo a la regulación de leyes predecibles, consistentes y legitimas. Es aquí, por tanto, donde la sociedad tiene un papel fundamental para empujar y lograr que estas medidas se implementen. Ello requeriría antes, como hace años lo dejó atinadamente señalado María Amparo Casar, una verdadera transición democrática consistente en cruzar de un corporativismo estatal a uno social (Casar, 1989). Esto exige, desde luego, volver a re-pensar el encadenamiento entre los centros gremiales (o corporaciones) y aquello que hoy día constituye formalmente el otro pilar de la representación regional y estatal en México: los partidos políticos y los movimientos electorales (Alvarado, 1990).

Concluyo con lo siguiente. Partir de un buen diagnóstico es el primer paso para llegar a una solución. He insistido en la existencia de una relación endógena entre corrupción y democracia. Su comportamiento está mutuamente condicionado. 
Sin embargo, lo que en realidad he querido probar es que democracia y corrupción guardan también relación con toda una otra serie de variables igualmente endógenas (históricas, regulatorias e institucionales). Confío que estas variables puedan servir de base para futuros estudios empíricos que tiendan a confirmar las hipótesis teóricas que aquí he desarrollado. También en que las coordenadas de reflexión que hemos asentado sirvan como un primer paso para adentrarse a entender los procesos de corrupción que amenazan a la democracia.

\section{Referencias}

Acemoglu, D. \& Robinson, J. (2012). Why Nations Fail. Nueva York: Crown Publishers. Traducido al castellano por Marta García Madera. 2012. Barcelona: Ediciones culturales Paidós.

Alvarado, A. (1990). El poder y su organización en el México Posrevolucionario. En F. Cortes. (Comp.) México en el umbral del milenio. México: Centro de Estudios Sociológicos del Colegio de México.

Astorga, L. (2010). México: de la seguridad autoritaria a la inseguridad de la transición democrática. En J.G. Tokatian (Ed.), Drogas y Prohibición. Una vieja guerra, un nuevo debate. México: Libros Zorzal.

Baum, M. A., y Lake D. A. (2003). The political Economy of Democracy and Human Capital. American Journal of Political Science 47, pp. 333-347.

Bizberg, I. (1990). La crisis del corporativismo mexicano. Foro Internacional, vol. 30, Núm.4 (120), pp.695-735.

Buscaglia, E. (2013). Vacíos de poder en México. México: Debate.

Casar, A., Marván, I., y Puente, K. (2012). La rendición de cuentas y el poder legislativo. Biblioteca Jurídica, pp.331-405. México: Instituto de Investigaciones Jurídicas, UNAM.

Casar, A. (1989). Corporativismo y transición. Nexos, num.137.

Clastres, P. (1983). Society Against the State. New York: Zone Books.

CNN en español. (2018, 25 de junio). México: una campaña pasada por sangre y fuego con 120 políticos asesinados. Recuperado de: https://cnnespanol.cnn. com/2018/06/25/mexico-violencia-campana-120-politicos-asesinados/

Organización de Naciones Unidas. (2004). Convención de las Naciones Unidas contra la corrupción Recuperado de: https://www.unodc.org/pdf/corruption/publications_unodc_convention-s.pdf

Curcó, F. (2010). La guerra Perdida. México: Ediciones Coyoacán.

Chowdhury, S. K. (2004). The effect of democracy and mass media on corruption: an empirical test. Economics Letters. 85 (1). pp. 93-101. 
Deninger, K., y Lyn, Squire. (1996). A New Data Set Measuring Income Inequality. World Bank Economic Review, 10, pp.565-591.

Diamond, J. (1997). Guns, Germs and Steel. Nueva York: Norton and Co.

Drury, K., \& Lusztig, M. (2006). Corruption, Democracy and Economic Growth. International Political Science Review, 27 (2), pp.121-136.

Fisman, R., \& Gatti, R. (2002). Decentralisation and corruption: evidence across countries. Journal of Public Economics (83), pp. 325-345.

García-García, A. (2006). El precio político de la venta de cargos públicos. Illes i imperis (9), pp.131-147.

Gilly, A. (1971). La revolución interrumpida. México: Ediciones El Caballito.

Gorbaneff, Y. (2001). Teoría del agente-principal y el mercadeo. Revista Universidad EAFIT (129), pp. 75-86

Hayek, F. (1973). Law, Legislation and Liberty. Chicago: Chicago University Press.

Helliwell, J. F. (1994). Empirical Linkages Between Democracy and Economic Growth. British Journal of Political Science (24), pp.225-248.

Kolstad, I., \& Wiig, A. (2016). Does democracy reduce corruption? Democratization, 23 (7), pp. 1198-1215.

Kubbe, I. (2015). Corruption in Europe: Is it all about democracy? Germany: Nomos Verlagsgesellschaft.

Langseth, P. (1999). Prevention: An Effective Tool to Reduce Corruption. United Nations Office for Drug Control and Crime Prevention. Viena, 2. December. Centre for International Crime Prevention. Global Program Against Corruption Conferences, pp. 2-38.

Mauro, P. (1995). Corruption and Growth. The Quarterly Journal of Economics. 110 (3). pp. 681-712.

Montinola, G. R., \& Jackman, R. W. (2002). Sources of corruption: A cross-country study. British Journal of Political Science, 32 (1), pp. 147-170.

Olteanu, T. (2012). Korruption in der Demokratie. En: T. Olteanu (Ed.), Korrupte Demokratie? Wiesbaden, VS Verlag für Sozialwissenschaften, pp.267-294.

Przeworski, A. (2000). Democracy and the Limits of Self-Government. New York: Cambridge University Press.

Przeworski, A.. Entrevista. Disponible, en: https://www.enperspectiva.net/ en-perspectiva-programa/entrevistas/politologo-adam-przeworski-lademocracia-no-es-algo-que-se-tenga-que-definir-en-terminos-estandarespara-todo-el-mundo/

Rose-Ackerman, S. (1996). The Political Economy of Corruption: Causes and Consequences. View Point. World Bank. 74, pp. 1-4. 
Rose-Ackerman, S. (2008). Corruption. En: C. K. Rowley \& F. G. Schneider (Eds.), Readings in public choice and Constitutional Political Economy. Boston, Springer US, pp.551-566.

Salazar, J. L. (2006). Cooperación Internacional en la Lucha contra la Delincuencia Organizada. En: A. Roemer y E. Buscaglia (Comp.), Terrorismo y Delincuencia Organizada: un enfoque de derecho y economía. México: UNAM.

Schmitter, P. (1994). Still the Century of Corporativism? The Review of Politics, January, pp 93-94.

Schmitter, P. \& Lehmbruch, G. (1992). Neocorporativismo Iy II. México: Alianza Editorial.

Transparency International. (2010). Why Corruption Matters. [Online]. Recuperado de: http://www.transparency.org.uk/corruption/why-it-matters.

Treisman, D. (2000). The causes of corruption: a cross-national study. Journal of Public Economics.76, pp. 399-457.

Weber, M. (2002). The protestant Ethic and the Spirit of Capitalism. Nueva York, Penguin.

Victoria, J., y Pérez, D. (2005). Corrupción y contrabando en la Nueva España del siglo XVIII: la continuidad de una práctica. En: A. Gutiérrez y M.L. Laviana (cords.), Estudios sobre América Latina: siglos xvi-xx. Sevilla: Asociación Española de Americanistas.

Ugalde, L. C. (2015). ¿Por qué más democracia significa más corrupción? Revista Nexos, febrero, pp.1-23. 